\title{
Crystallization kinetics of poly (butylene adipate terephthalate) in biocomposite with coconut fiber
}

\section{Cinética de cristalização do poli (butileno adipato tereftalato) em biocompósitos com fibra de côco}

\author{
Jokdérlea Correa Sousa ${ }^{1}$, Salim Abdelnor Arruda ${ }^{1}$, Juliana Cisneiros Lima ${ }^{1}$, \\ Renate Maria Ramos Wellen ${ }^{2}$, Eduardo Luis Canedo ${ }^{3}$, \\ Yêda Medeiros Bastos de Almeida ${ }^{1}$
}

\footnotetext{
${ }^{1}$ Chemical Engineering Department, Federal University of Pernambuco, 50.740-520, Recife, Pernambuco, Brazil.

${ }^{2}$ Materials Engineering Department, Federal University of Paraíba, 58.051-900, João Pessoa, Paraíba, Brazil.

${ }^{3}$ Materials Engineering Department, Federal University of Campina Grande, 58.429-900, Campina Grande, Paraíba, Brazil.

e-mail: yedamba@gmail.com
}

\section{RESUMO}

Os parâmetros da cristalização a partir do fundido de um composto de fibras lignocelulósicas de côco dispersas em poli (butileno adipato tereftalato) (PBAT), uma matriz de copoliéster totalmente biodegradável, foi estudada por calorimetria exploratória diferencial (DSC). Os compostos de PBAT/fibra de côco com $10 \%$ e $20 \%$ de fibra foram preparados num misturador interno de laboratório; a reometria de torque mostrou degradação insignificante durante o processamento. A cristalização não-isotérmica a partir do fundido da matriz foi estudada por DSC em compostos com $10 \%$ de fibra com taxas de resfriamento entre 2 e $32^{\circ} \mathrm{C} / \mathrm{min}$, e informações quantitativas foram fornecidas em temperaturas e taxas de cristalização, bem como a cristalinidade desenvolvida, que apresentou valor maior do que o esperado nas altas taxas de resfriamento. Os resultados cinéticos da cristalização foram correlacionados usando modelos clássicos macrocinéticos: Pseudo-Avrami, Ozawa e Mo, para obter expressões analíticas quantitativas apropriadas para o processamento. Os modelos Pseudo-Avrami e Mo representaram bem os dados experimentais. Uma análise detalhada da modelagem é apresentada, a fim de avaliar as incertezas esperadas. Apesar de desvios observados no início e no final do processo de cristalização, o modelo Mo é recomendado como a melhor correlação empírica geral dos dados experimentais para o propósito pretendido.

Palavras-chave: PBAT, fibra vegetal, cristalização a partir do fundido, modelos cinéticos.

\section{ABSTRACT}

The melt crystallization characteristics of a compound of coconut lignocellulosic fibers dispersed in poly(butylene adipate terephthalate) (PBAT), a fully biodegradable copolyester matrix, was studied by differential scanning calorimetry (DSC). PBAT/coconut fiber compounds with $10 \%$ and $20 \%$ filler content were prepared in a laboratory internal mixer; torque rheometry showed negligible degradation during processing. Nonisothermal melt crystallization of the matrix was thoroughly studied by DSC in $10 \%$ compounds at cooling rates between 2 and $32^{\circ} \mathrm{C} / \mathrm{min}$, and quantitative information was provided on crystallization temperatures and rates, as well as the crystallinity developed, which turned out to be higher than expected at the high cooling rates. Crystallization kinetic results were correlated using classical macrokinetic Pseudo-Avrami, Ozawa, and Mo models, in order to obtain quantitative analytical expressions appropriate for processing applications. Pseudo-Avrami and Mo models were found to represent well the experimental data. A detailed analysis of the model fitting is presented, in order to assess the expected uncertainties. Despite its failings at the onset and end of the crystallization process, Mo model is recommended as best overall empirical correlation of the experimental data for the intended purpose. 
Keywords: PBAT, vegetable fiber, melt crystallization, kinetic models.

\section{INTRODUCTION}

Persistent polymers are an important source of environmental pollution. New materials with environmentally friendly characteristics, included biodegradable polymers, have attracted considerable attention in last decades. Among the new polymers, poly(butylene adipate-co-butylene terephthalate) (PBAT) appears as a promising option. [1-3]

PBAT is a biodegradable, semi-crystalline, random aliphatic-aromatic copolyester based on the monomers 1,4-butanediol, adipic acid and terephthalic acid. When metabolized in soil or compost under standard conditions it biodegrades to carbon dioxide, water and biomass. [4-7]

Commercialized by BASF (Germany) under the trade name Ecoflex®, PBAT has properties similar to low density polyethylene. Rigid aromatic units confer excellent mechanical and physical properties to aliphatic-aromatic copolyesters, while retaining the biodegradability promoted by aliphatic units. Particular applications of PBAT include cling wrap for food packaging, compostable plastic bags for gardening and agricultural use, water resistant coatings for other materials, etc. Due to its high flexibility and biodegradable nature, PBAT is also marketed as an additive for more rigid biodegradable plastics, to impart flexibility while still maintaining the full biodegradability of the blend. [2,8]

In the present contribution coconut fiber, also known as coir, is compounded into PBAT by melt mixing, taking advantage of a readily available and inexpensive filling extracted from the outer shell of the coconut. The vegetable filler has as main constitutes lignin (46\%) and cellulose (44\%), and has found a limited use in the manufacture of rope, fishing nets, brushes, doormats, rugs, mattresses, and in insulation panels and packaging. In Europe, the automobile industry upholsters cars with pads of brown coir bonded with rubber latex. Also, it has been successfully used in polymeric and ceramic compounds. [9]

Final properties of PBAT are determined by the supramolecular structure, which depends in part on the crystallization conditions. The addition of a natural filler, such as coconut fiber, may affect PBAT morphology and crystallization behavior. Therefore, it may be interesting to characterize the crystalline development of PBAT in natural fiber reinforced compounds. Crystallization kinetics affects optimum processing protocols and the viability of manufacturing particular items, and allows the rational control of the compound morphology. [10-12]

In the present work the nonisothermal crystallization of PBAT/coconut fiber was studied by differential scanning calorimetry (DSC). Classical macrokinetic models of Pseudo-Avrami, Ozawa, and Mo were applied to the data in order to obtain quantitative correlations apt for processing applications. Activation energy was estimated using a modified Friedman isoconversional model-free kinetics approach.

\section{EXPERIMENTAL}

The polymer matrix is basically a random copolymer of 1,4-butanodiol adipate and 1,4-butanodiol terephthalate, with a 1:1 molar ratio of comonomers, which will be identified here as PBAT. The actual material, a commercial grade known as Ecoflex ${ }^{\circledR}$ F BX7011 supplied by BASF, contains - according to manufacturer's sources [13] - small quantities of a custom polyfunctional comonomer that may allow some (unknown) degree of branching in the otherwise linear structure of PBAT. Density at ambient temperature (ISO 1183) was reported as $1,26 \mathrm{~g} / \mathrm{cm}^{3}$ and melt flow rate (ISO 1133) as 3-8 $\mathrm{cm}^{3} / 10 \mathrm{~min}$; PBAT is a rubbery amorphous polymer at ambient temperature $\left(T_{g}=-30^{\circ} \mathrm{C}\right)$ [8]. Preliminary tests suggest that PBAT melts between $50^{\circ} \mathrm{C}$ and $150^{\circ} \mathrm{C}$, with a peak at $120^{\circ} \mathrm{C}$, and has a low degree of crystallinity (around 15\%) [14-15].

Coconut fiber, extracted from the outer layers of the fruit (coco) of the palm Cocos nucifera L (Arecaceae), is commonly used in gardening as a porous, highly hygroscopic substrate. The material used, supplied by local vendors, was thoroughly dried and screened to select a fraction with particle size between 0.25 to $0.50 \mathrm{~mm}$.

Compounds with $10 \%$ and $20 \%$ filler (by weight) were prepared in a laboratory internal mixer Haake Rheomix 3000 fitted with high intensity (roller type) rotors, operated at a $60 \mathrm{rpm}$ nominal rotor speed for 15 min, with the chamber wall kept at $160^{\circ} \mathrm{C}$ and a $70 \%$ fill factor. The neat polymer was processed in the same way to provide a baseline for comparison.

DSC tests were conducted with samples of the PBAT compound with $10 \%$ coconut fibers in a MetterToledo DSC-1 instrument with 5 to $7 \mathrm{mg}$ samples under nitrogen flow $(50 \mathrm{~mL} / \mathrm{min})$. A three-stage temperature program was used: heating from $25^{\circ} \mathrm{C}$ to $180^{\circ} \mathrm{C}$, cooling to $25^{\circ} \mathrm{C}$ and reheating to $180^{\circ} \mathrm{C}$. Tests were conducted at nine heating/cooling rates: $2,3,4,6,8,12,16,24$, and $32^{\circ} \mathrm{C} / \mathrm{min}$. DSC output during the cool- 
ing stage was integrated with custom software to obtain PBAT melt crystallization parameters as functions of cooling rate.

\section{RESULTS AND DISCUSSION}

\subsection{Torque rheometry}

Torque $(Z)$ and temperature $(T)$ were recorded as functions of time $(t)$ during processing samples of PBAT and PBAT/fiber compounds with $10 \%$ and $20 \%$ fiber in the laboratory internal mixer with mixer chamber wall kept at $160^{\circ} \mathrm{C}$, as shown in Figure 1 .
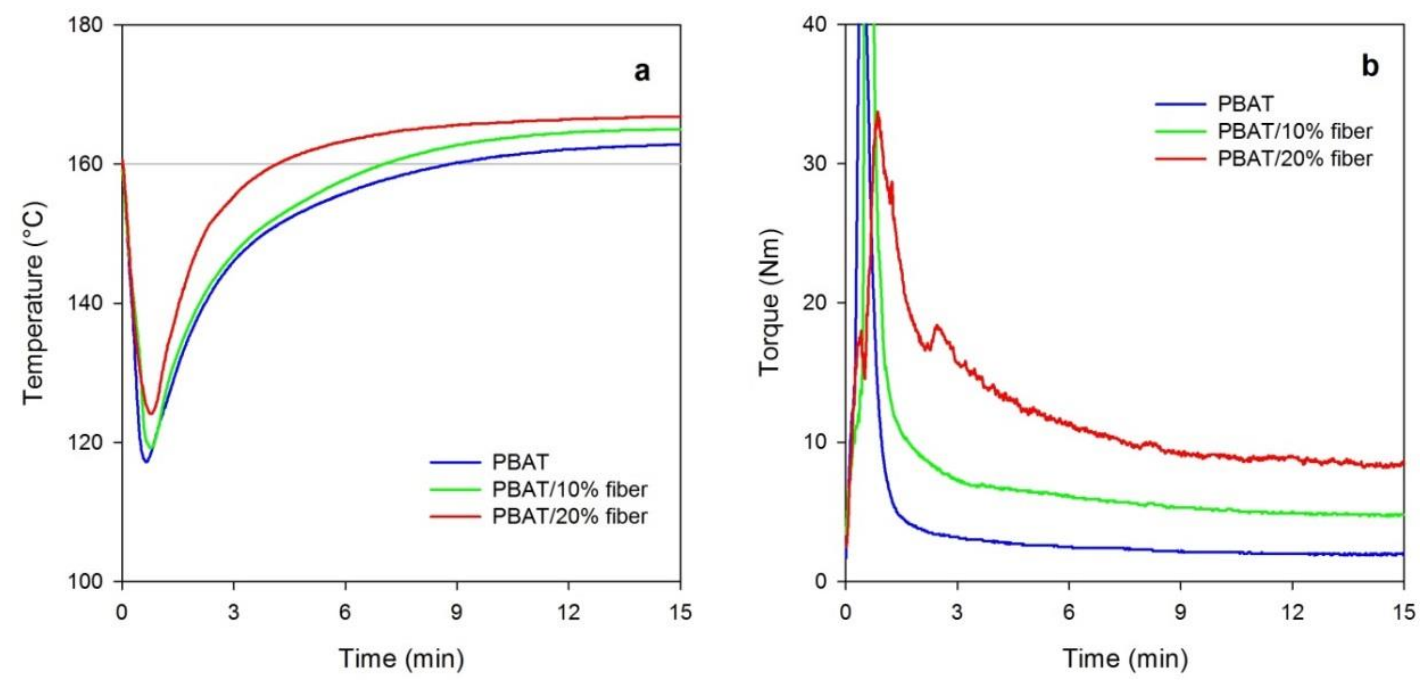

Figure 1: Temperature (a) and torque (b) versus time for the processing of PBAT and PBAT/fiber compounds in the internal mixer.

Material is substantially molten after 5 min processing; temperature rises and torque gently drops after that, with values depending (increasing) as the filler content increases. Torque being proportional to melt viscosity, its value at a given filler concentration depends on polymer molar mass and temperature. To isolate the former effect, it is convenient to reduce the torque to a reference temperature [16]:

$$
Z^{*}=Z \exp \left\{\beta\left(T-T^{*}\right)\right\}
$$

where $T^{*}$ is an arbitrary reference temperature and $\beta$ is the exponential temperature coefficient of the viscosity of the matrix, which may taken as $\beta=0,025{ }^{\circ} \mathrm{C}^{-1}$ for PBAT [6]. In filled melts, viscosity - thus, torque - depends on the filler level [17]; under the terminal processing conditions tested an increase of reduced torque with filler content is expected (and observed). On the other hand, variation of reduced torque with time indicates changes in the matrix molar mass, usually a decrease resulting from thermal degradation, which may be induced or accelerated in the presence of the filler. Table 1 shows the mean values of temperature, torque and reduced torque (at $T^{*}=160^{\circ} \mathrm{C}$ ) for the last $5 \mathrm{~min}(10$ to $15 \mathrm{~min})$ processing. Figure 2 shows the evolution of the reduced torque with time.

Table 1: Average temperature, torque and reduced torque $\left(T^{*}=160^{\circ} \mathrm{C}\right)$ for $10-15 \mathrm{~min}$ of processing in the internal mixer.

\begin{tabular}{l|l|l|l}
\hline \multirow{2}{*}{ SYSTEM } & $\mathbf{T}$ & $\mathbf{Z}$ & $\mathbf{Z}^{*}$ \\
\cline { 2 - 4 } & $\left({ }^{\circ} \mathrm{C}\right)$ & $(\mathrm{Nm})$ & $(\mathrm{Nm})$ \\
\hline PBAT & 162.1 & 2.0 & 2.1 \\
\hline PBAT/10\% fiber & 164.5 & 4.9 & 5.6 \\
\hline PBAT/20\% fiber & 166.5 & 8.6 & 10.4 \\
\hline
\end{tabular}




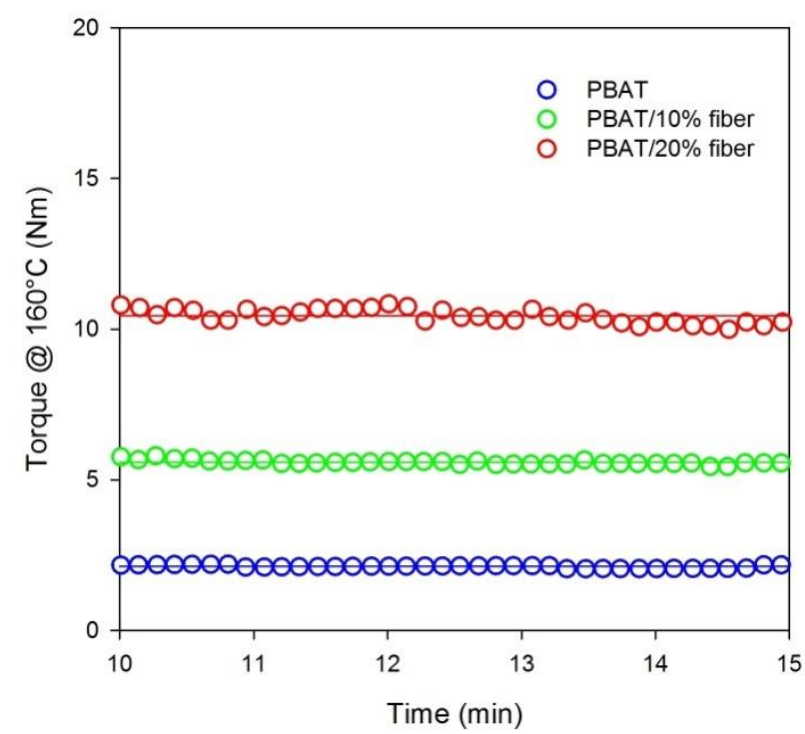

Figure 2: Reduced torque versus time during the last $5 \mathrm{~min}$ of processing of PBAT and PBAT/fiber compounds in the internal mixer.

The constancy or reduced torque suggests the absence of degradation for all filler content levels tested. PBAT behaves as a stable resin under processing conditions.

\subsection{Melt crystallization}

Time $(t)$, sample temperature $(T)$ and heat flow $(J)$ registered by the instrument at $1 \mathrm{~s}$ intervals were integrated, using a suitable virtual baseline $\left(J_{0}\right)$ and onset/end points visually determined $\left(t_{1}, t_{2}\right)$, for the melt crystallization event. Custom software was employed to obtain the relative crystallinity $(x)$ and rate of crystallization $(c)$ as functions of time and temperature:

$$
\begin{aligned}
& x(t)=\frac{1}{E_{0}} \int_{t_{1}}^{t}\left|J\left(t^{\prime}\right)-J_{0}\left(t^{\prime}\right)\right| d t^{\prime} \\
& c(t)=\frac{d x}{d t}=\frac{\left|J(t)-J_{0}(t)\right|}{E_{0}}
\end{aligned}
$$

where

$$
E_{0}=\int_{t_{1}}^{t_{2}}\left|J(t)-J_{0}(t)\right| d t
$$

is the total latent heat of phase change. Time and temperature are related through the constant rate of cooling, $\phi=|d T / d t|$ :

$$
T=T_{1}-\phi\left(t-t_{1}\right)
$$

From the functions $x(T)$ and $c(T)$ a series of characteristic crystallization parameters were estimated, including the initial, mean, and final temperatures $T_{0.1 \%}, T_{50 \%}$ and $T_{99.9 \%}$, peak crystallization temperature $T_{c}$, maximum crystallization rate $c_{\max }$, and half-crystallization time $\tau_{1 / 2}$. Mass crystallinity recovered during the event was estimated as $[12,18]$ :

$$
\Delta X_{c}=\frac{\Delta H_{c}}{\Delta H_{m}^{0}}=\frac{E_{0}}{m_{S} w_{P} \Delta H_{m}^{0}}
$$

where $m_{S}$ is the sample mass, $w_{\mathrm{P}}$ is the mass fraction of the polymer (PBAT) and $\Delta H_{m}^{0}$ is the latent 
heat of meting of a 100\% crystalline polymer, taken in the present work as $114 \mathrm{~J} / \mathrm{g}$ [19].

Reproducibility tests reported elsewhere [15] suggests that uncertainties of $\pm 0.2^{\circ} \mathrm{C}$ in temperatures and $2 \%$ in crystallinity are attainable with the equipment and technique employed with PBAT/vegetable fiber compounds.

Data were collected for neat PBAT and for 10\% and 20\% vegetable fiber compounds. Qualitatively similar results were obtained for all three formulations. Results for PBAT/10\% coconut fiber are presented in detail as an example. Figures 3 and 4 show the relative crystallinity $x=x(T)$ and rate of crystallization $c=$ $c(T)$ for the melt crystallization of PBAT in the compound with $10 \%$ filler at all cooling rates tested. Table 2 collects some thermodynamic and kinetic parameters of the event.

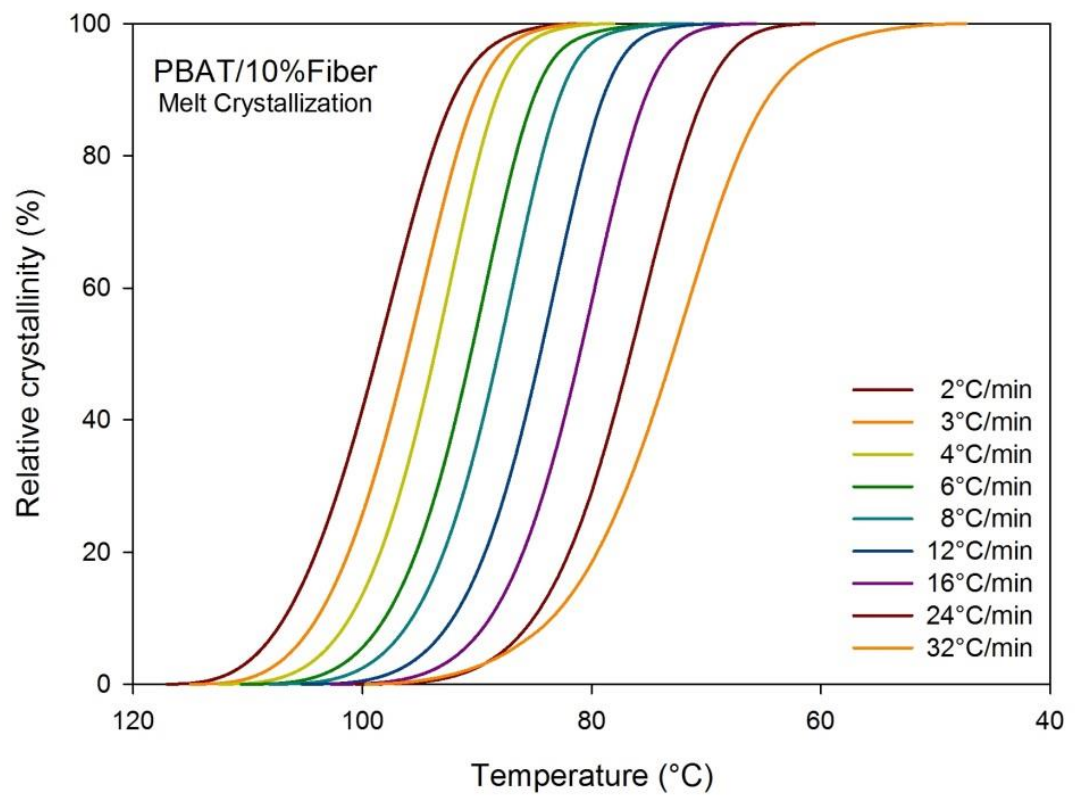

Figure 3: Relative crystallinity versus temperature for the melt crystallization of PBAT in the compound with $10 \%$ coconut fiber at different cooling rates (indicated).

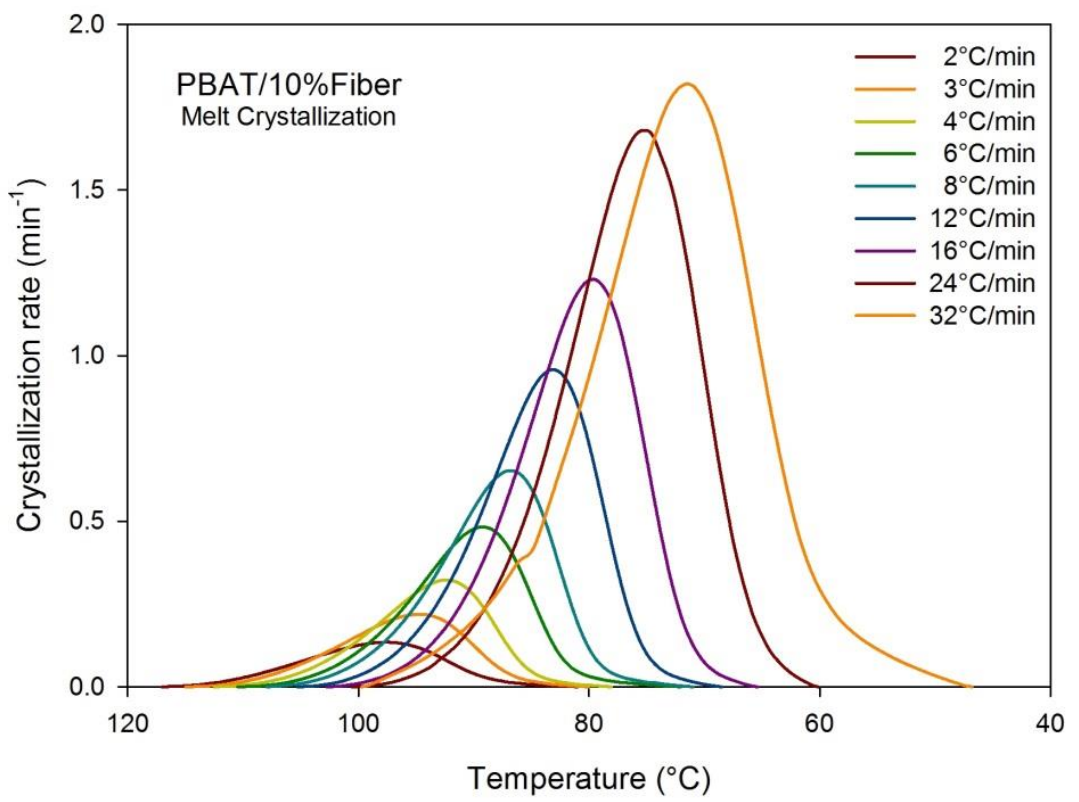

Figure 4: Rate of crystallization versus temperature for the melt crystallization of PBAT in the compound with $10 \%$ coconut fiber at different cooling rates (indicated). 
Table 2: Melt crystallization parameters.

\begin{tabular}{|c|c|c|c|c|c|c|c|c|}
\hline$\phi$ & $T_{0,1 \%}$ & $T_{50 \%}$ & $T_{99,9 \%}$ & $T_{c}$ & $c_{\max }$ & $\tau_{1 / 2}$ & $\Delta H_{c}$ & $\Delta X_{c}$ \\
\hline$\left({ }^{\circ} \mathrm{C} / \mathrm{min}\right)$ & \multicolumn{4}{|c|}{$\left({ }^{\circ} \mathrm{C}\right)$} & $\left(\min ^{-1}\right)$ & $(\min )$ & $(\mathrm{J} / \mathrm{g})$ & $(\%)$ \\
\hline 2 & 115.2 & 98.7 & 82.5 & 97.4 & 0.135 & 8.27 & 16.8 & 11.5 \\
\hline 3 & 112.7 & 96.1 & 81.7 & 94.8 & 0.219 & 5.54 & 17.4 & 11.9 \\
\hline 4 & 110.2 & 93.7 & 79.9 & 92.5 & 0.322 & 4.13 & 18.4 & 12.6 \\
\hline 6 & 107.6 & 90.6 & 74.6 & 89.3 & 0.483 & 2.85 & 19.9 & 13.6 \\
\hline 8 & 105.5 & 88.2 & 73.4 & 86.8 & 0.653 & 2.17 & 19.7 & 13.4 \\
\hline 12 & 102.3 & 84.5 & 70.8 & 83.1 & 0.958 & 1.49 & 20.9 & 14.3 \\
\hline 16 & 96.7 & 81.1 & 67.6 & 79.6 & 1.230 & 1.17 & 21.4 & 14.6 \\
\hline 24 & 96.9 & 76.6 & 62.2 & 75.2 & 1.681 & 0.85 & 23.6 & 16.1 \\
\hline 32 & 97.7 & 72.9 & 49.7 & 71.5 & 1.821 & 0.78 & 33.2 & 22.7 \\
\hline
\end{tabular}

Crystallization proceed around a temperature interval slightly over $30^{\circ} \mathrm{C}$, at decreasing temperatures as the cooling rate increases, $97^{\circ} \mathrm{C}$ at $2{ }^{\circ} \mathrm{C} / \mathrm{min}$ to $72^{\circ} \mathrm{C}$ at $32^{\circ} \mathrm{C} / \mathrm{min}$. The rate of crystallization rises sharply, keeping pace with the cooling rate (10 to 14 times increase in crystallization rate over a 16 times increase in cooling rate); Crystallinity increases moderately with the cooling rate: from $11.5 \%$ at $2{ }^{\circ} \mathrm{C} / \mathrm{min}$ to 22.7 at $32^{\circ} \mathrm{C} / \mathrm{min}$. These results may be attributed to the higher super-cooling (diving force) required to melt crystallize the PBAT at higher cooling rates. Figure 5 shows these trends graphically.
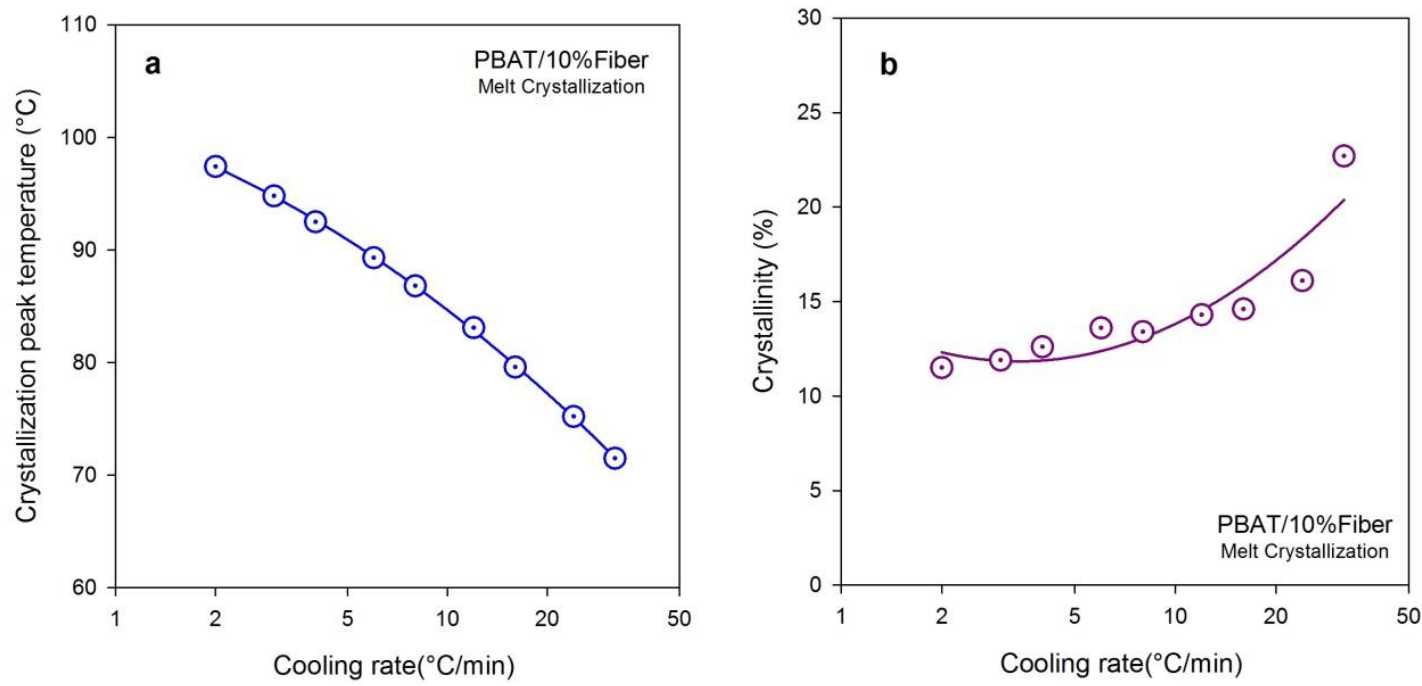

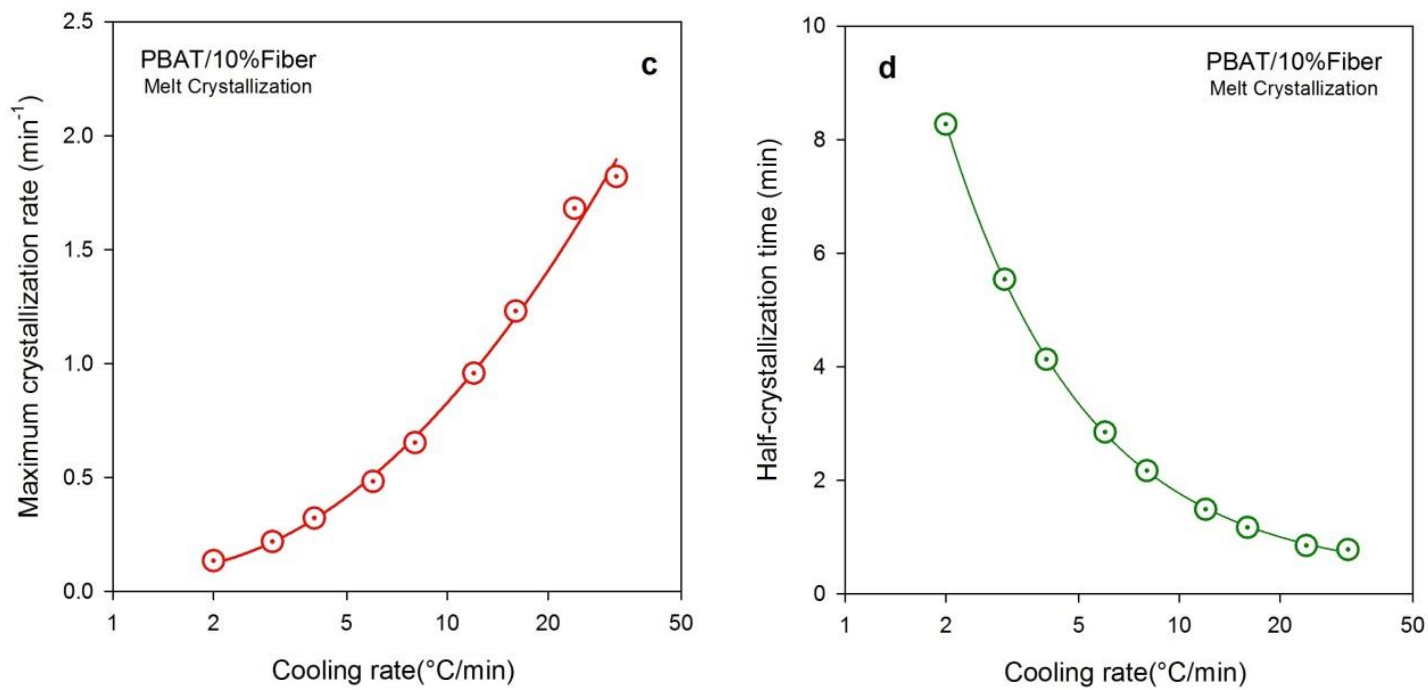

Figure 5: Melt crystallization parameters in $\mathrm{PBAT} / 10 \%$ fiber compound as functions of the cooling rate.

\subsection{Crystallization kinetics}

\subsubsection{Pseudo-Avrami model}

Pseudo-Avrami model correlates relative crystallinities $x$ with time measured from the onset of the event $\tau$ at constant cooling rate $\phi$ :

$$
x=1-\exp \left(-K \tau^{n}\right)
$$

Model parameters $K$ e $n$ are functions of the cooling rate $\phi$; exponent $n$ is dimensionless and the dimension of $K$ depends on the exponent $\left(\min ^{-n}\right.$ in the present case) [20-21]. Parameters are obtained from a linear regression of the Avrami function $y=y(x)$ :

$$
y=\ln \left(-\ln \frac{1}{1-x}\right)=\ln K+n \ln \tau
$$

Since the relation between $y$ and $\ln \tau$ is seldom linear over the whole range of crystallization times, a suitable interval of approximate linearity should be selected; in this work we give priority to values for 5 to 95\% relative crystallinity. Figure 6 shows three examples of the Avrami plot and Table 3 collect the PseudoAvrami parameters estimated for all conditions tested. 


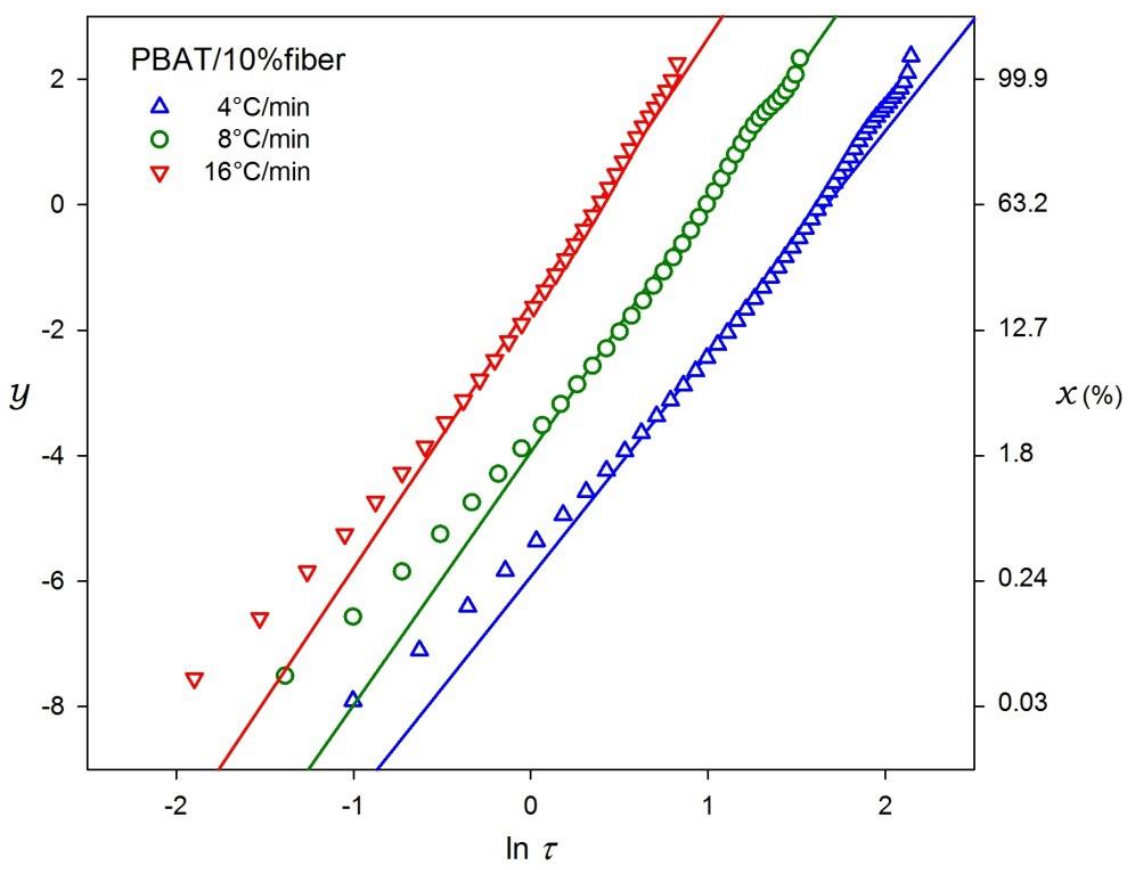

Figure 6: Avrami plots for PBAT/10\% fiber compounds run at three cooling rates: experimental results (symbols), Pseudo-Avrami correlation (lines).

Table 3: Pseudo-Avrami parameters.

\begin{tabular}{c|c|c|c}
\hline$\phi\left({ }^{\circ} \mathbf{C} / \mathbf{m i n}\right)$ & $\ln \boldsymbol{N}$ & $\boldsymbol{r}^{2}$ \\
\hline 2 & $-7.351 \pm 0.012$ & $3.174 \pm 0.006$ & 0.997 \\
\hline 3 & $-6.540 \pm 0.009$ & $3.325 \pm 0.006$ & 0.999 \\
\hline 4 & $-5.924 \pm 0.014$ & $3.552 \pm 0.012$ & 0.998 \\
\hline 6 & $-5.126 \pm 0.020$ & $3.993 \pm 0.019$ & 0.996 \\
\hline 8 & $-3.943 \pm 0.020$ & $4.035 \pm 0.023$ & 0.995 \\
\hline 12 & $-2.566 \pm 0.016$ & $4.170 \pm 0.028$ & 0.995 \\
\hline 16 & $-1.569 \pm 0.013$ & $4.223 \pm 0.032$ & 0.995 \\
\hline 24 & $-0.292 \pm 0.013$ & $4.324 \pm 0.033$ & 0.996 \\
\hline
\end{tabular}

(parameter $K$ in $\min ^{-n}$ )

It should be noted that Pseudo-Avrami model is only an empirical correlation procedure for nonisothermal results obtained at constant heating/cooling rate. Pseudo-Avrami parameters - unlike the formally similar Avrami parameters for isothermal crystallization - have no physical meaning.

Pseudo-Avrami parameters for melt crystallization of PBAT/10\% fiber compounds could be correlated in terms of the cooling rate:

$$
\begin{array}{ll}
\ln K=-8.4506+1.2296(\ln \phi)+0.4345(\ln \phi)^{2} & \left(r^{2}=0.996\right) \\
n=2.4237+1.0823(\ln \phi)-0.1525(\ln \phi)^{2} & \left(r^{2}=0.972\right)
\end{array}
$$

Figure 7 shows the results. 

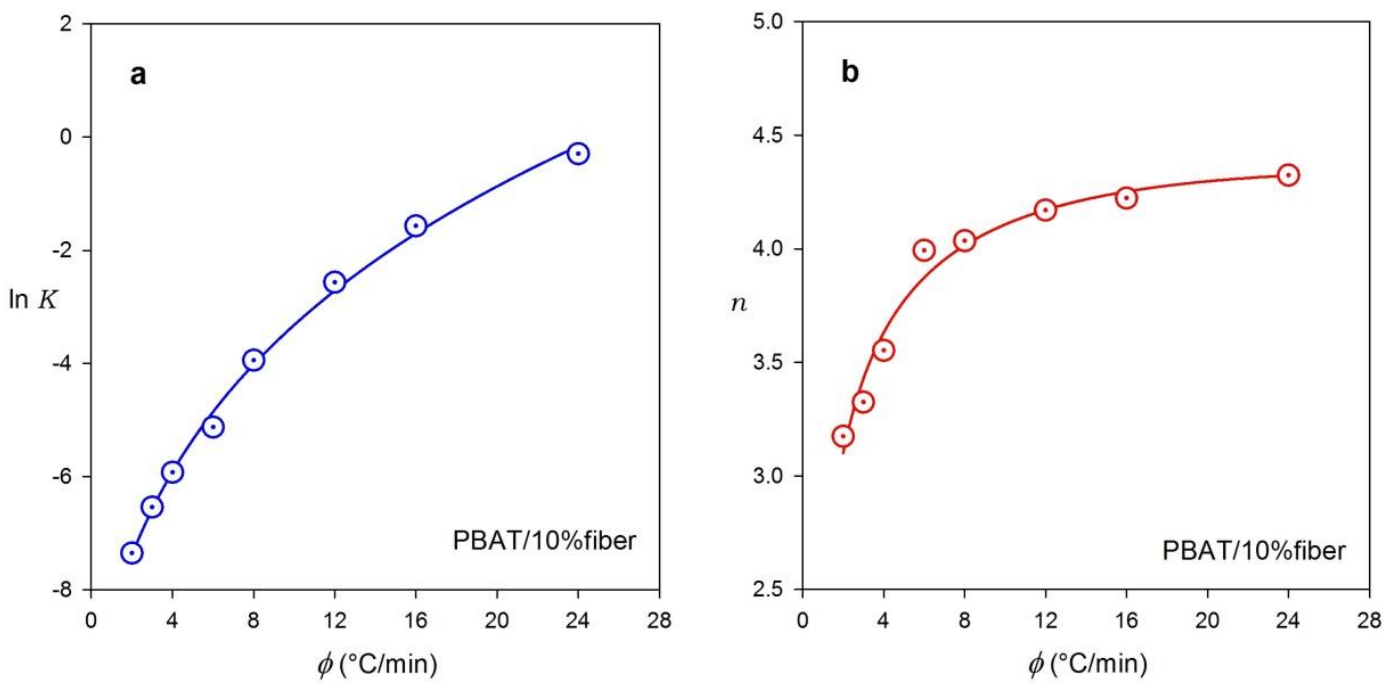

Figure 7: Pseudo-Avrami parameters for PBAT/10\% fiber compounds as functions of the cooling rate: correlation results (symbols) and Eq.(9) fits (lines).

Figure 8 compares experimental and Pseudo-Avrami predicted values of relative crystallinity for the three examples shown in Figure 6. Agreement is fairly good over the whole interval of temperatures.

A quantitative estimate of the discrepancies is better presented by plotting a discrepancy function:

$$
\Delta_{\mathrm{PSAv}}=x_{\mathrm{pre}}-x_{\mathrm{exp}}
$$

where $x_{\text {pre }}$ and $x_{\text {exp }}$ are predicted and experimental values of the relative crystallinity.

The question arises of how to compute the "predicted values". Figure 9a is plotted with predicted values based on parameters estimated for specific, discrete values of the cooling rate. However, processing applications require a continuum specter of cooling rates, which necessitate interpolation of model parameters. Figure $9 \mathrm{~b}$ is plotted with predicted values based on parameters computed by Eq.(9).

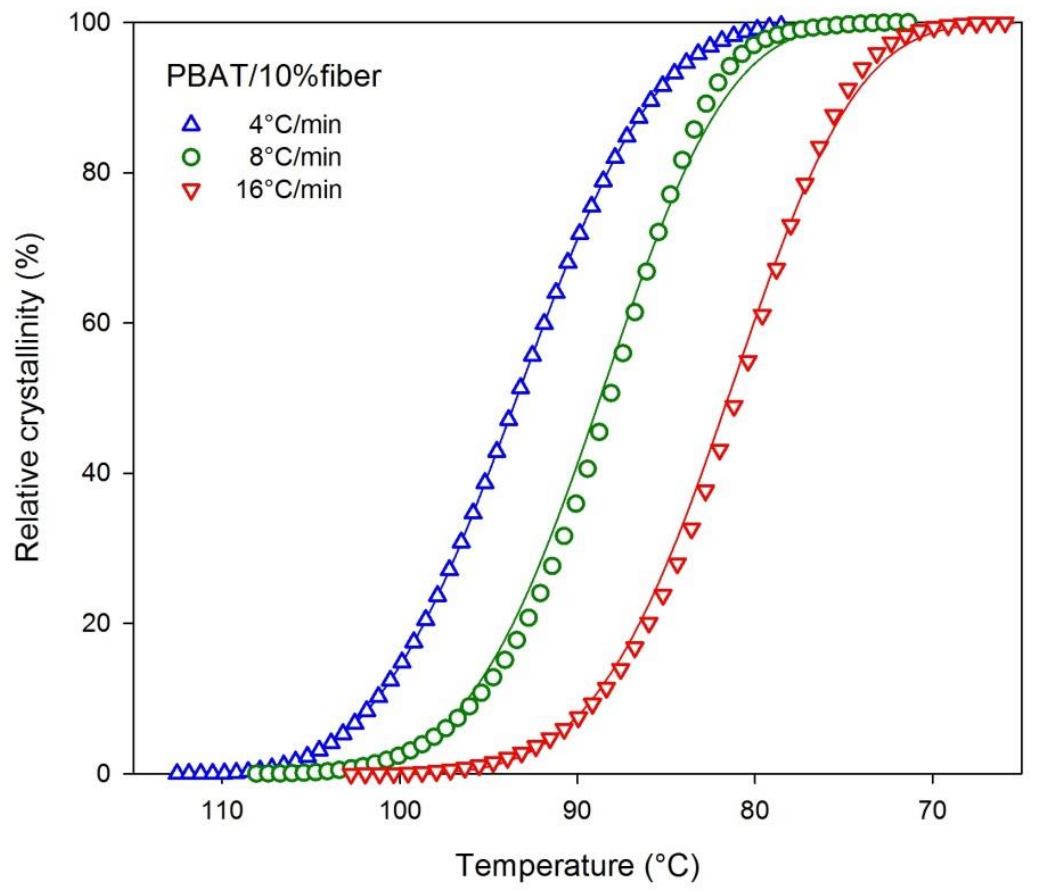

Figure 8: Experimental results (symbols) and Pseudo-Avrami model predictions (lines) for melt crystallization in PBAT $10 \%$ fiber compounds at three cooling rates. 

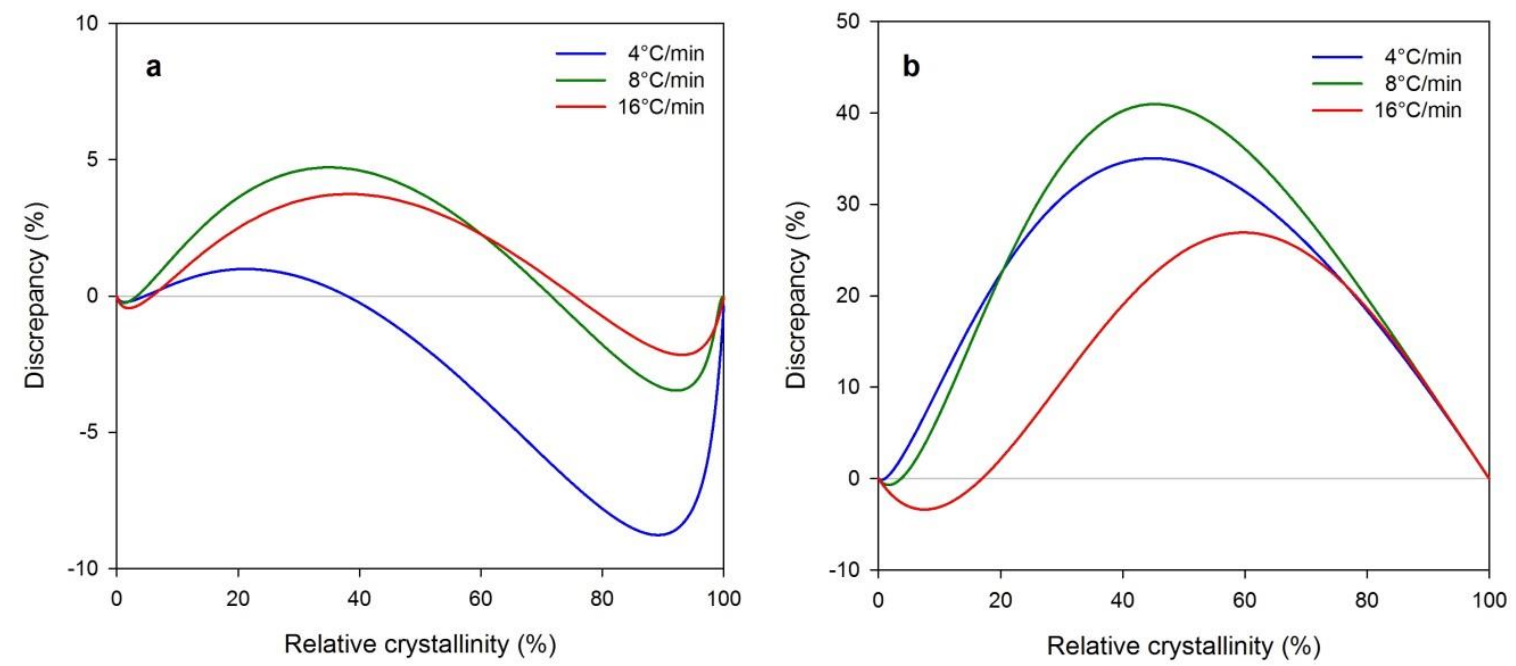

Figure 9: Discrepancy between the experimental values of relative crystallinity and those predicted by the PseudoAvrami correlation, using the parameters estimated for each cooling rate (a) and the parameters computed by Eq.(9), for melt crystallization in PBAT/10\% fiber compounds.

While estimated based on individual model parameter is very reasonable, with discrepancies between 5 to $10 \%$, correlated parameters result in large discrepancies, between 20 to $40 \%$ in the critical region close the peak crystallization rate, pointing to the weakness of Pseudo-Avrami model as a correlation procedure: individual tests result in good prediction but when the issue is to quantitatively predict the crystallization behavior at arbitrary cooling rates, its performance is disappointing.

\subsubsection{Ozawa model}

Ozawa model [22] correlates relative crystallinities $x$ with cooling rate $\phi$ at constant temperature $T$ :

$$
x=1-\exp \left(-\kappa \phi^{-m}\right)
$$

requiring interpolation of the experimental data, which are measured a constant cooling rate. Parameters $\kappa$ and $m$ are functions of the temperature; exponent $m$ is dimensionless and the dimension of $\kappa$ depends on the exponent, $\left({ }^{\circ} \mathrm{C} / \mathrm{min}\right)^{m}$ in the present case. Parameters are obtained from a linear regression of the Avrami-Ozawa function $y=y(x)$ :

$$
y=\ln \left(-\ln \frac{1}{1-x}\right)=\ln \kappa+m \ln \phi
$$

Figure 10 shows the Ozawa plot based on all conditions tested, for temperatures between $110^{\circ} \mathrm{C}$ and $70^{\circ} \mathrm{C}$ in $5^{\circ} \mathrm{C}$ intervals. 


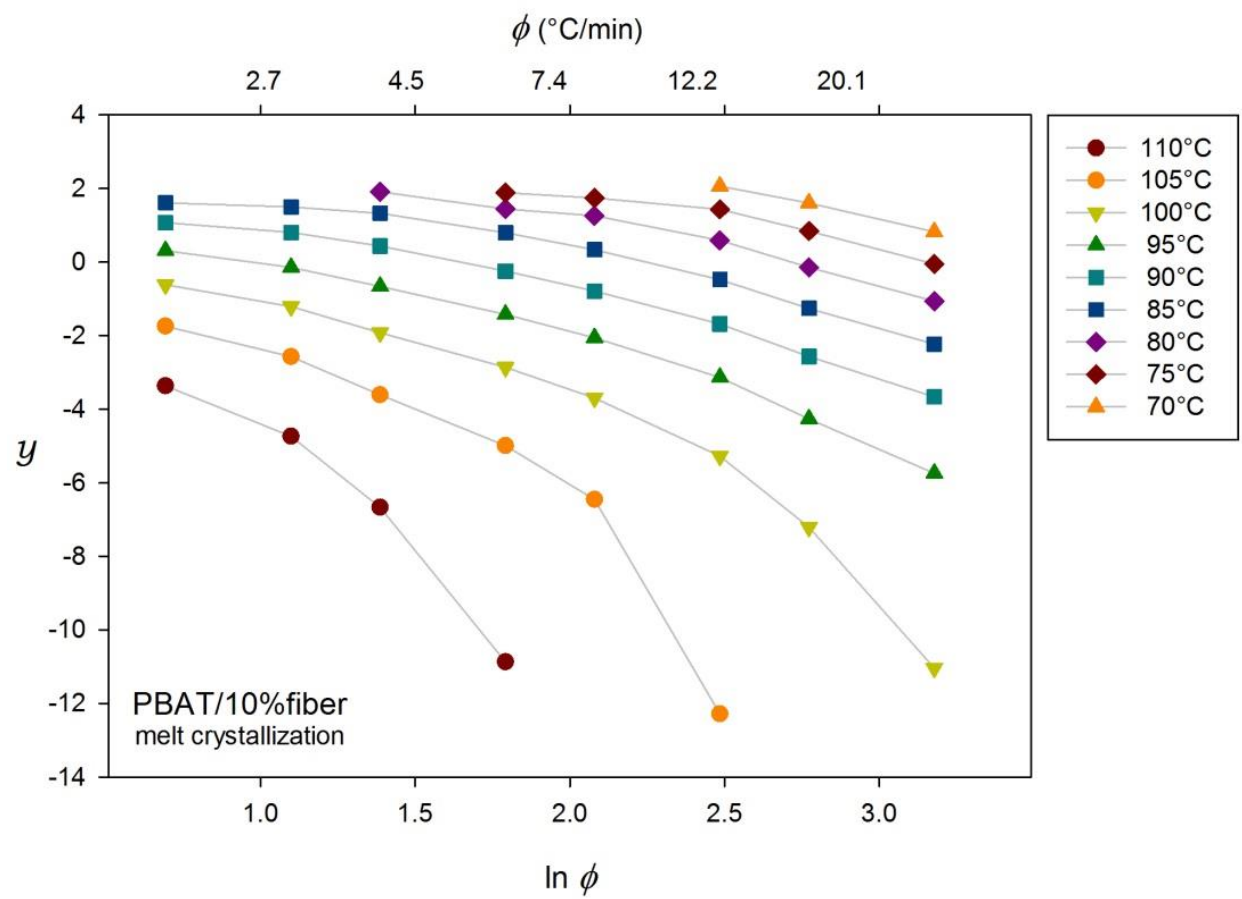

Figure 10: Ozawa plots for PBAT/10\% fiber compounds at all cooling rates tested.

The plots show clearly that the Avrami-Ozawa functions do not depend linearly on $\ln \phi$; thus Ozawa model is not applicable to the system under the conditions tested, as it does not fit the experimental data. Sometimes a piecewise linear fitting is forced upon part of the data [17, 23], but this is not a good practice, especially if we are seeking quantitative correlations for use in processing applications.

\subsubsection{Mo model}

Mo and coworkers [24-25] proposed a model that correlates the cooling rate $\phi$ with crystallization time $\tau$ at constant relative crystallinity $x$ :

$$
\phi=F \tau^{-\alpha}
$$

Application of the model requires interpolation of the experimental data measured a constant cooling rate. Parameters $F$ and $\alpha$ are functions of the relative crystallinity; exponent $\alpha$ is dimensionless and the dimension of $F$ depends on the exponent $\left(\min ^{\alpha}\right.$ in the present case). Parameters are obtained from a linear regression of:

$$
\ln \phi=\ln F-\alpha \ln \tau
$$

Figure 11 shows four examples of the Mo plot and Table 4 collects Mo parameters based on all conditions tested, estimated for $0.1 \leq x \leq 0.9$ in $\Delta x=0,1$ intervals. 


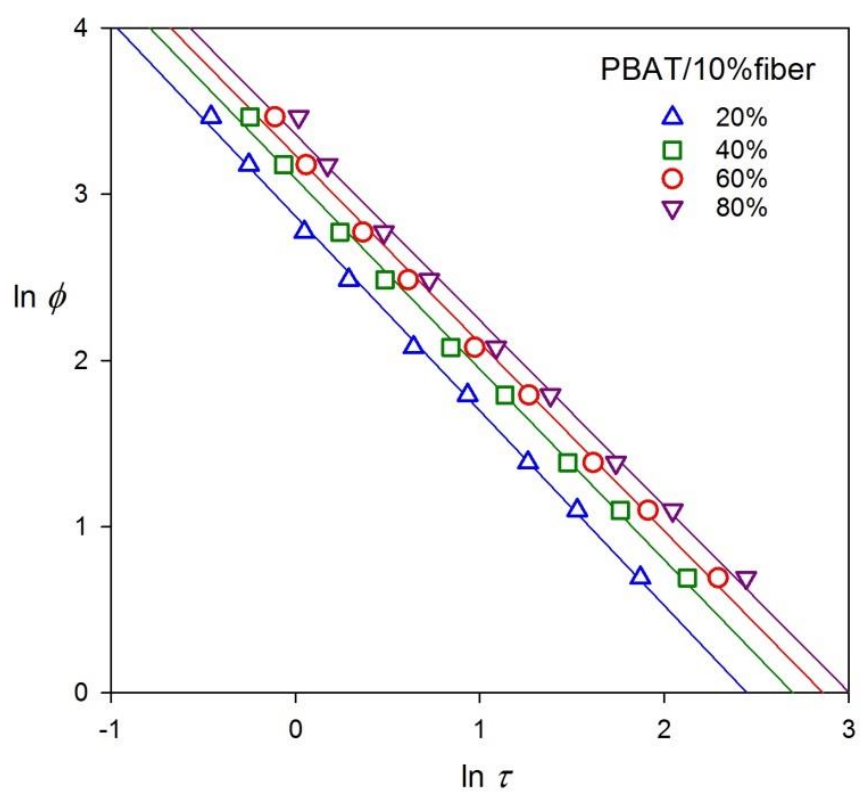

Figure 11: Mo plots for PBAT/10\% fiber compounds run at three cooling rates: experimental results (symbols), Mo correlation (lines).

Mo model appears to fit well experimental data, with uncertainties of 2 to $5 \%$ in pre-exponential parameter $F$ and exponent $\alpha$ virtually independent of relative crystallinity.

Table 4: Mo parameters.

\begin{tabular}{c|c|c|c}
\hline $\boldsymbol{x}(\%)$ & $\ln \boldsymbol{F}$ & $\boldsymbol{\alpha}$ \\
\hline 10 & $2.213 \pm 0.021$ & $0.841 \pm 0.009$ & 1.000 \\
\hline 20 & $2.447 \pm 0.028$ & $0.853 \pm 0.012$ & 1.000 \\
\hline 30 & $2.589 \pm 0.033$ & $0.862 \pm 0.014$ & 0.998 \\
\hline 40 & $2.694 \pm 0.037$ & $0.870 \pm 0.016$ & 0.100 \\
\hline 50 & $2.780 \pm 0.041$ & $0.876 \pm 0.018$ & 0.997 \\
\hline 60 & $2.855 \pm 0.044$ & $0.882 \pm 0.019$ & 0.997 \\
\hline 70 & $2.924 \pm 0.048$ & $0.886 \pm 0.021$ & 0.996 \\
\hline 90 & $2.995 \pm 0.052$ & $0.890 \pm 0.023$ & 0.995 \\
\hline 90 & $3.080 \pm 0.059$ & $0.893 \pm 0.026$ & 0.994 \\
\hline
\end{tabular}

(parameter $F$ in $\min ^{\alpha}$ )

Mo parameters for melt crystallization of PBAT/10\% fiber compounds could be correlated in terms of the relative crystallinity:

$$
\begin{array}{ll}
\ln F=1.944+3.144 x-3.963 x^{2}+2.085 x^{3} & \left(r^{2}=0.999\right) \\
\alpha=0.826+0.157 x-0.139 x^{2}+0.053 x^{3} & \left(r^{2}=1.000\right)
\end{array}
$$

Figure 12 shows the results. 

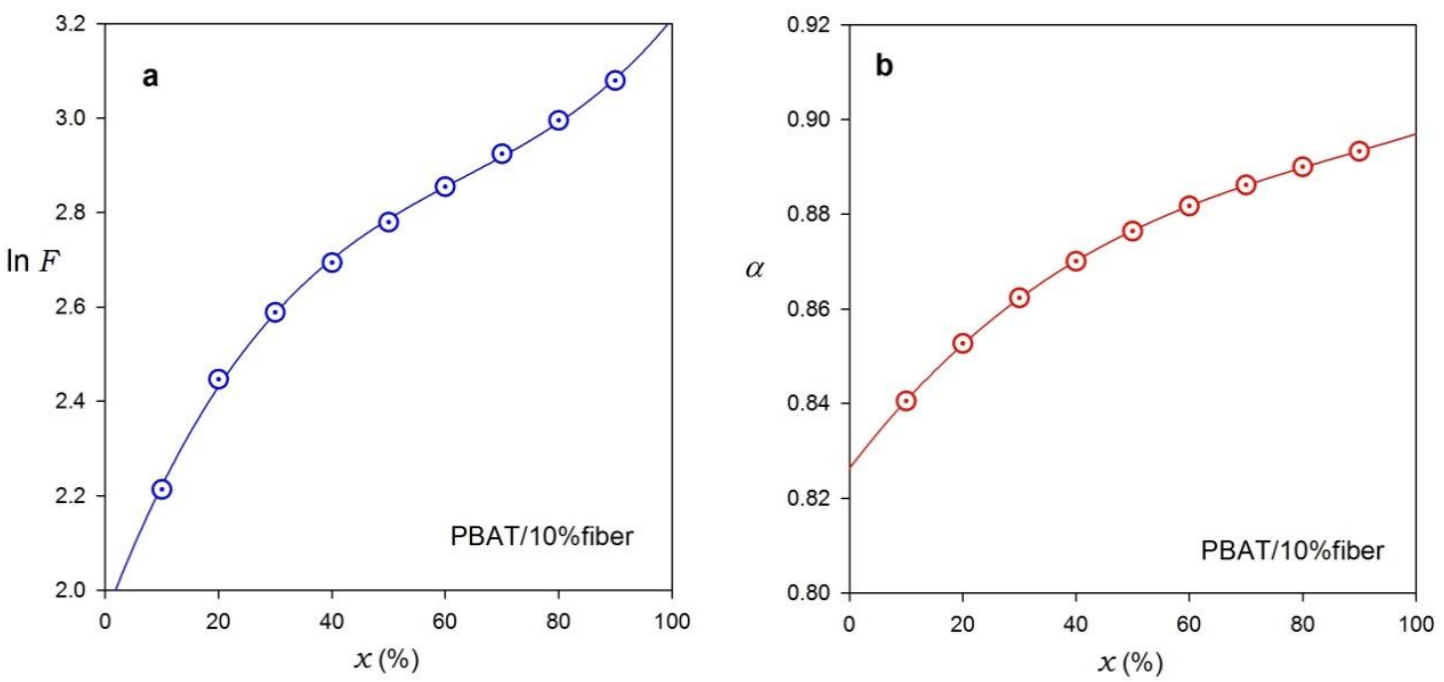

Figure 12: Mo parameters for PBAT/10\% fiber compounds as functions of the cooling rate: correlation results (symbols) and Eq.(15) fits (lines).

These are very smooth plots, which facilitate interpolation. However, the ultimate test of model suitability, the comparison of experimental and predicted values are only adequate, as shown in Figure 13.

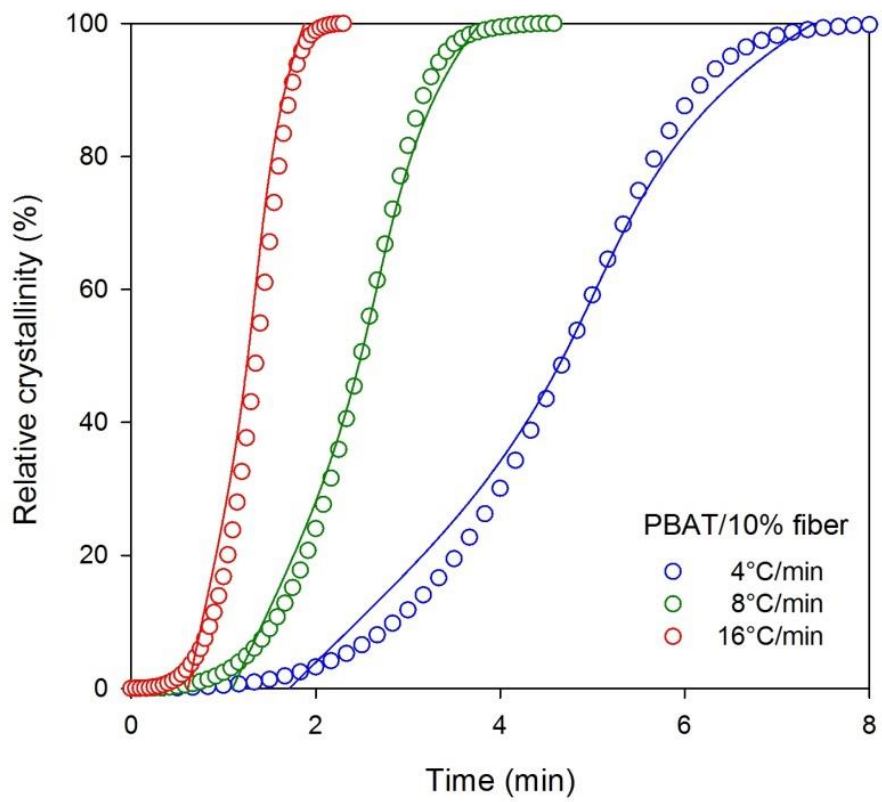

Figure 13: Experimental results (symbols) and Mo model predictions (lines) for melt crystallization in PBAT/10\% fiber compounds at three cooling rates.

The inability to properly represent the results for very low and very high values of the relative crystallinity (the onset and end of the process) is a characteristic of the Mo model.

Experimentally, the sigmoids $x=x(\tau)$ have vanishing inclination limits (i.e., null crystallization rate for $x \rightarrow 0$ and $x \rightarrow 1$ ). Differentiation of the Mo model, Eq.(13), for constant exponent $\alpha$ results in the differential form of the model:

$$
c=\left(\frac{d x}{d \tau}\right)_{\phi}=\frac{\alpha \phi^{1 / \alpha} F^{1-1 / \alpha}}{(d F / d x)}
$$

Correct modelling at the extremes requires very high (ideally infinity) values of $d F / d x$, which is not 
the case for the dataset under consideration.

A quantitative estimate of the discrepancies is better presented by plotting a relative time discrepancy function, normalized using the half crystallization times $\tau_{\frac{1}{2}}$ (cf. Table 2 ):

$$
\Delta_{\mathrm{Mo}}=\frac{\tau_{\text {pre }}-\tau_{\text {exp }}}{\tau_{1 / 2}}
$$

where $\tau_{\text {pre }}$ and $\tau_{\text {exp }}$ are predicted and experimental times, measured from the onset of the melt crystallization event, as shown in Figure 14. Predicted values are based on parameters computed by Eq.(15).

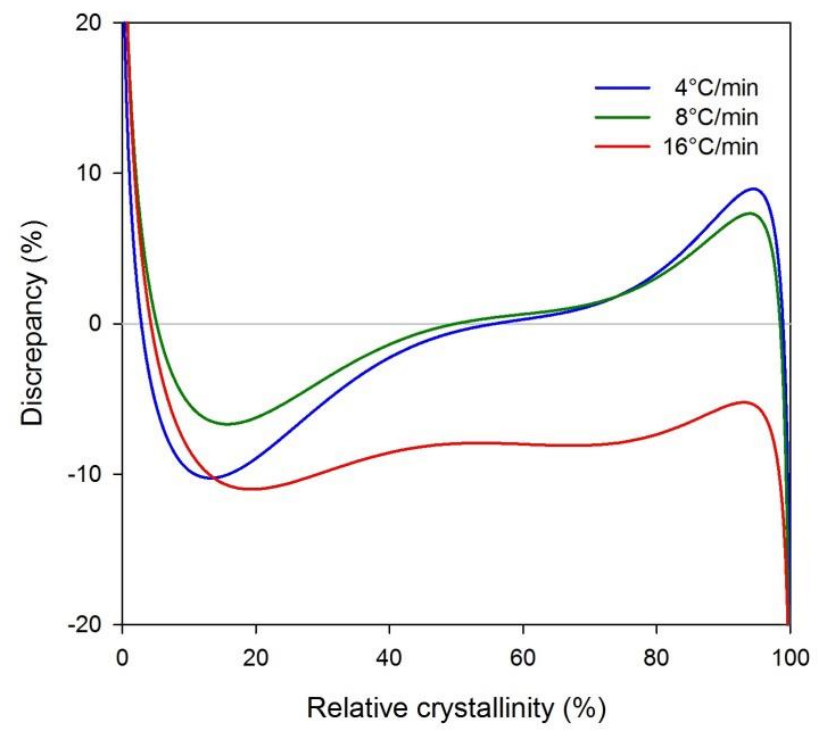

Figure 14: Discrepancy between the experimental values of relative crystallinity and those predicted by the Mo correlation, using the parameters computed by Eq.(15), for melt crystallization in PBAT/10\% fiber compounds.

\subsubsection{Activation energy}

Activation energy is considered a basic kinetic parameter in all thermally induced process, including polymer crystallization. The classical procedure of Kissinger [26-27] to estimate activation energies in nonisothermal reactions from the dependence of peak temperature on the heating rate cannot be applied to process that take place during cooling [28-29], such as melt crystallization. However, model-free isoconversional kinetic methods are entirely appropriate. Among them, Friedman procedure [30].

Overall activation energies are defined assuming that the rate can be expressed as a product of two factors: one (the so called rate constant) that is function of temperature and other that is function of the conversion (the relative crystallinity in the present case). Furthermore, the kinetic constant is assumed to depend exponentially on the reciprocal of temperature (Arrhenius dependence) measured in the absolute scale (which we may symbolize with the Greek capital $\Theta$ ):

$$
c=\frac{d x}{d \tau}=k(T) \cdot f(x)=k_{0} \exp \left\{-\frac{E_{a}}{R \Theta}\right\} f(x)
$$

or

$$
\ln c=\ln k_{0}+\ln f-\frac{E_{a}}{R \Theta}
$$

where $k_{0}$ is a constant pre-exponential factor, $E_{a}$ is the activation energy, and $R=8.315 \mathrm{~kJ} / \mathrm{mol} \cdot \mathrm{K}$ is the universal gas constant.

If assumptions leading to Eqs.(18)-(19) are valid for the system under study a plot $\ln c$ versus $\Theta^{-1}$ at 
constant relative crystallinity results in a straight line. The activation energy $E_{a}$ is then estimated by a linear regression of the experimental data. In the present case, melt crystallization rates are computed directly from experimental data collected at different constant cooling rates, which required interpolation to convert them to constant relative crystallinity. The resulting activation energy is, in general, a function of the conversion.

Figure 15a shows Friedman plot for the melt crystallization of PBAT in PBAT compounds with $10 \%$ fiber content.
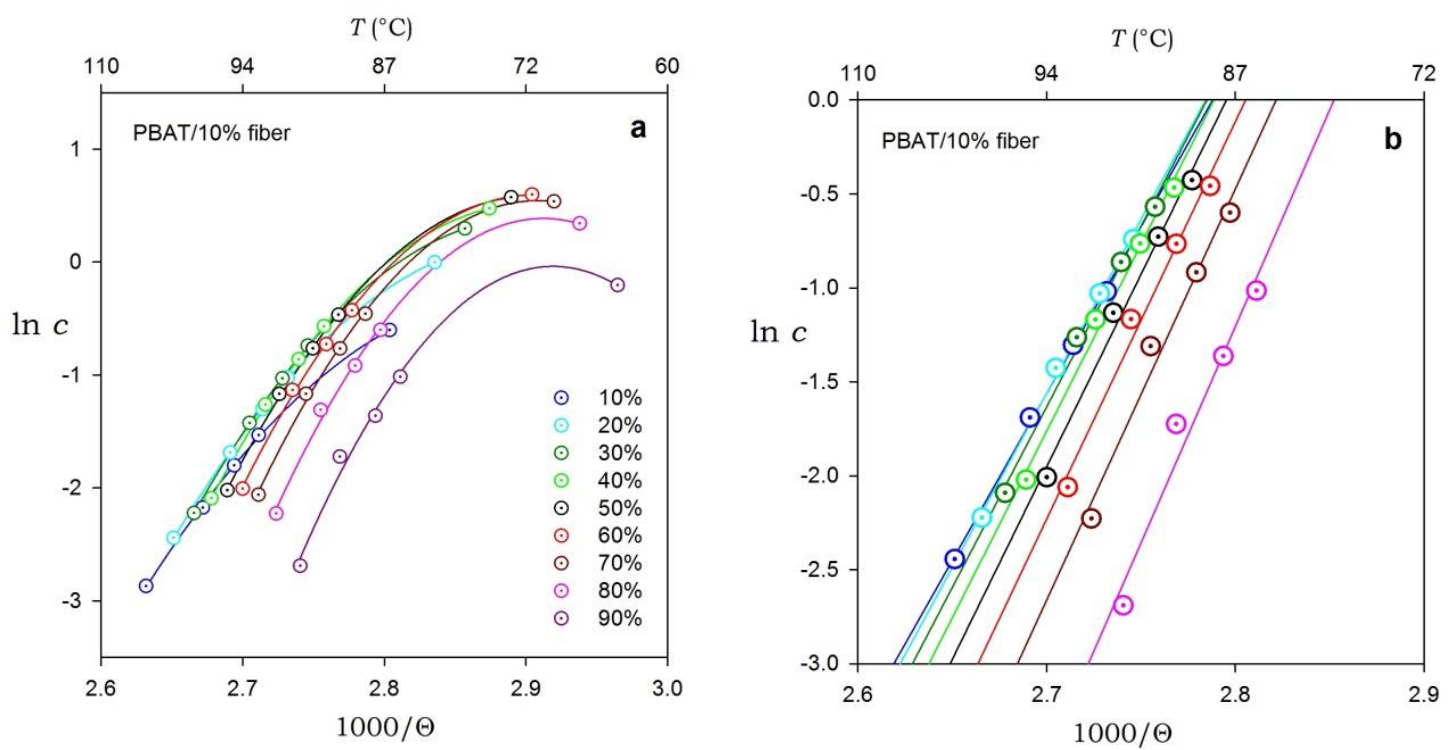

Figure 15: Friedman plot to estimate the activation energy: complete dataset showing the nonlinearity (a) and reduced, approximately linear dataset (b).

Considered over the whole relative crystallinity interval, experimental crystallization rate is not proportional to the exponential of reciprocal absolute temperature, as shown in Figure 15a. However a reduced data set, excluding low crystallinites $(x<20 \%)$ and considering only temperatures above $80^{\circ} \mathrm{C}$ shows sufficient linearity to justify the estimate of activation energies by the Friedman method. The activation energy based on the reduced dataset, as shown in Figure 15b, is virtually independent of the conversion:

$$
E_{a}=-167 \pm 5 \mathrm{~kJ} / \mathrm{mol}
$$

It is generally agreed that negative activation energies are an indication of complex nature of the processes involved in polymer crystallization from the melt [10,31]. Moreover, the concept of "model free kinetics" in general and negative activation energies in particular has been debated in the technical literature [32-34]. The alternative view, that the Arrhenius description of the temperature dependence of the kinetic constant for melt crystallization process - simple or complex - is not appropriate should also be considered.

\section{CONCLUSIONS}

Thermally stable compounds where obtained by melt mixing under selected processing conditions, a fact confirmed by torque rheometry. Melt crystallization temperature decreased and crystallization rate increased with cooling rate, as expected; crystallinity increased significantly with cooling rate, a result which was not expected. Nonisothermal melt crystallization kinetics was well correlated by Pseudo-Avrami and Mo models, not so by Ozawa's. Quantitative assessment of goodness of fit of model predicted data revealed that low uncertainty of the model parameters, as determined by the standard correlation methods, not always translates in good prediction of experimental results by interpolating a limited set of experimental DSC data. Overall, Mo's model is recommended for applications that require an analytic expression crystallinity versus time or temperature.

\section{ACKNOWLEDGEMENTS}

Authors would like to thank BASF for kindly supplying PBAT. The authors also thank Conselho Nacional de 
Desenvolvimento Científico e Tecnológico (CNPq - Brazil 306875/2015-2), Fundação de Amparo à Ciência e Tecnologia do Estado de Pernambuco (FACEPE - Brazil) and Programa de Recursos Humanos (PRH28/ANP - Brazil) for financial support.

\section{BIBLIOGRAPHY}

[1] NAIR, L. S., LAURENCIN, C. T., "Biodegradable polymers as biomaterials", Prog. Polym. Sci., v. 32, pp. 762-798, 2007.

[2] HERRERA, R., FRANCO, L., RODRIGUEZ-GALAN, A., PUIGGALI, J., "Characterization and degradation behavior of poly(butylene adipate-co-terephthalate)", J. Polym. Sci. Pol. Chem., v. 40, pp. 4141-4157, 2002.

[3] LÖRCKS, J., "Properties and applications of compostable starch-based plastic material", Polym. Degrad. Stabil., v. 59, pp. 245-249, 1998.

[4] MOHANTY, A. K., MISRA, M., HINRICHSEN, G., "Biofibres, biodegradable polymers and biocomposites: An overview”, Macromol. Mater. Eng., v. 276-277, pp. 1-24, 2000.

[5] FENG, S., WU, D., LIU, H., et al., "Crystallization and creep of the graphite nanosheets based poly(butylene adipate-co-terephthalate) biocomposites", Thermochim Acta, v. 587, pp. 72-80, 2014.

[6] COSTA, A. R. M., ALMEIDA, T. G., SILVA, S. M. L., et al., "Chain extension in poly(butyleneadipate-terephthalate).Inline testing in a laboratory internal mixer", Polym. Test., v. 42, pp. 115-121 2015.

[7] WITT, U., MULLER, R. J., DECKWE, W. D., "Biodegradation behavior and material properties of aliphatic/aromatic polyesters of commercial importance", J. Environ. Polym. Degrad., v. 5, pp. 81-89, 1997.

[8] BASF, Product Information: Ecoflex ${ }^{\circledR}$ F-Blend C1200. Biodegradable polyester for compostable film, 2013.

[9] FAO, Future fibers: coir. www.fao.org/economic/futurefibres/fibres/coir. Accessed 05-10-2016.

[10] RIES, A., CANEDO, E. L., MONTEIRO, A. E. G., et al., "Model-free non-isothermal crystallization kinetics of poly(3-hydoxybutyrate) filled with carbon black", Polym. Test., v. 50, pp. 241-246, 2015.

[11] VITORINO, M. B. C., CIPRIANO, P. B., WELLEN, R. M. R., et al., "Nonisothermal Melt Crystallization of PHB/Babassu Compounds. Kinetics of Crystallization", J. Therm Anal. Calorim., v. 126, pp. 755-769, 2016.

[12] WELLEN, R. M. R., CANEDO, E. L., RABELLO, M. S., "Melting and crystallization of poly(3hydroxybutyrate)/carbon black compounds. Effect of heating and cooling cycles on phase transition", $J$. Mater. Res., v. 30, pp. 3211-3226, 2015.

[13] YAMAMOTO, M., WITT, U., SKUPIN, G., et al., Biodegradable Aliphatic-Aromatic Polyesters: Ecoflex®. Steinbüchel (ed.), Elsevier: New York, 2002.

[14] COSTA, A. R. M., Chain extension of poly (butylene-adipate-terephthalate) with epoxidic polyfunctional additive. MSc Thesis, Federal University of Campina Grande, Campina Grande PB, Brazil, 2015.

[15] SOUSA, J. C., Systhesis and crystallization kinetics of biocomposite PBAT/coconut fiber. MSc Thesis, Federal University of Pernambuco, Recife PE, Brazil, 2015.

[16] ALVES, T. S., NETO, J. E. S., SILVA, S. M. L., et al., "Process simulation of laboratory internal mixers", Polym. Test., v. 50, pp. 94-100, 2016.

[17] SHENOY, A. V., Rheology of Filled Polymer Systems. Kluwer, Dordrecht, 1999.

[18] CANEDO, E. L., WELLEN, R. M. R., ALMEIDA, Y. M. B., Cristalização de Polímeros - Tratamento de Dados e Modelagem Macrocinética. ANP PRH-28/DEQ/UFPE, Recife, 2016.

[19] MONDAL, D., BHOWMICK, B., MOLLICK, M., et al., "Antimicrobial activity and biodegradation behavior of poly(butylene adipate-co-terephthalate)/clay nanocomposites", J. Appl. Polym. Sci., v. 131, pp. 40079-40088, 2014.

[20] JEZIORNY, A., "Parameters characterizing the kinetics of the non-isothermal crystallization of poly(ethylene terephthalate) determined by DSC", Polymer, v. 19, pp. 1142-1144, 1978.

[21] WELLEN, R. M. R., CANEDO, E. L., "Nonisothermal melt and cold crystallization kinetics of PHB and PHB/CB compounds. Evaluation of Pseudo-Avrami, Ozawa, and Mo models", J. Mater. Res., v. 31, pp. 729-739, 2016.

[22] OZAWA, T., "Kinetics of non-isothermal crystallization", Polymer, v. 12, pp. 150-158, 1971.

[23] WELLEN, R. M. R., CANEDO, E. L., RABELLO, M. S., "Nonisothermal cold crystallization of 
poly(ethylene terephthalate)", J. Mater. Res., v. 26, pp. 1107-1115, 2011.

[24] LIU, T., MO, Z., WANG, S., et al., "Nonisothermal melt and cold crystallization kinetics of poly(aryl ether ether ketone ketone)", Polym. Eng. Sci., v. 37, pp. 568-575, 1997.

[25] AN, Y., DONG, L., MO, Z., et al., "Nonisothermal crystallization kinetics of poly(3-hydoxybutyrate)", J. Polym. Sci. Part B: Polym. Phys., v. 36, pp. 1305-1312, 1998.

[26] KISSINGER, H. E., "Variation of peak temperature with heating rate in differential thermal analysis", $J$. Res., v. 57, pp. 217-221, 1956.

[27] KISSINGER, H. E., "Reaction kinetics in differential thermal analysis", Anal. Chem., v. 29, pp. 17021706, 1957.

[28] VYAZOVKIN, S., "Is the Kissinger equation applicable to the processes that occur on cooling?", Macromol. Rapid Commun., v. 23, pp. 771-775, 2002.

[29] WELLEN, R. M. R., CANEDO, E. L., "On the Kissinger equation and the estimate of activation energies for non-isothermal cold crystallization of PET", Polym. Test., v. 40, pp. 33-38, 2014.

[30] VYAZOVKIN, S., Isoconversional Kinetics of Thermally Stimulated Processes. Springer: Heidelberg, 2015.

[31] GALWEY, A. K., "Is the science of thermal analysis kinetics based on solid foundations?: A literature appraisal", Thermochim. Acta, v. 413, pp. 139-183, 2004.

[32] SEWRY, J. D., BROWN, J. D., “Model-free' kinetic analysis?”, Thermochim. Acta, v. 390, pp. 217-225, 2003.

[33] GALWEY, A. K., "What is meant by the term 'variable activation energy' when applied in the kinetics analyses of solid state decompositions (crystolysis reactions)?", Thermochim. Acta, v. 397, pp. 249-268, 2003.

[34] VYAZOVKIN, S., "Reply to <What is meant by the term 'variable activation energy' when applied in the kinetics analyses of solid state decompositions (crystolysis reactions)?>”, Thermochim. Acta, v. 397, pp 269-271, 2003.

\section{ORCID}

Jokderléa Corrêa de Sousa

Salim Abdelnor Arruda

Juliana Cisneiros Lima

Renate Maria Ramos Wellen

Eduardo Luis Canedo

Yêda Medeiros Bastos de Almeida https://orcid.org/0000-0003-1041-7144 https://orcid.org/0000-0002-9309-1719

https://orcid.org/0000-0002-9586-8472

https://orcid.org/0000-0002-8818-6131

https://orcid.org/0000-0002-3565-7366

https://orcid.org/0000-0003-3325-5803 